\title{
Can Albanian Port Area be Part of The European Network of Eco-Ports Based on Environmental Information systems?
}

\author{
Dr. Indrit Baholli ${ }^{1}$ \\ Alma Stana ${ }^{2}$ \\ Dr. Elvin Meka ${ }^{3}$ \\ Mimoza Karafili ${ }^{4}$

\begin{abstract}
1Department of Computer Sciences, European University of Tirana 2PhD Candidate"Aleksander Moisiu" University of Durres, Albania 3Department of Finance, European University of Tirana 4Msc, "Aleksander Moisiu" University of Durres, Albania Indrit.Baholli@uet.edu.al, stana_alma@yahoo.it, Elvin.Meka@uet.edu.al,mimozakarafili@hotmail.com
\end{abstract}

Doi:10.5901/jesr.2013.v3n2p139

\section{Abstract}

Nowadays, port areas can constitute the entry point and core place for sustainable development for the entire urban system with their dynamism. When these port areas are in the same time port cities, the eco-performance of these hotspots asks to balance economic prosperity with social needs and conservation of eco-systems in reinventing the city. Durres Port Authority, in accordance with national and European legislation, checks pollution in the port basin supporting the initiative for clean technologies at ports of Eighth Corridor partners of BariDurres-Varna. Since 2011, is presented the "New Eco Ports" as A New Era for Ecoports in Europe, using on-line systems for evaluating environmental performance of ports,. Can Albania be part of the European network of EcoPorts based on Environmental Information systems? This paper is focused on thecurrent analyse of Environmental Information Systems supporting the eco-performance monitoring ports in albanian ports. The study notes that Eco Ports Network Platform enables European port communities to exchange environmentally effective solutions, and work together in collaborative projects addressing sustainability issues in ports and the logistic chain. The novelty of this article is confronting of the Albanian port area with eco-European ports, in point of view to prevent the pollution of water, air and landbased in environment information systems. This paper will conclude with recomandations about this future challenge for albanian ports; how tobe part of the European network of EcoPorts based on Artificial Intelligence.

Keywords: Artificial Intelligence, platform, Environmental Information Systems, port.

\section{Introduction}

The objects of this study are Environmental Information Systems and their assistance to monitor the ports ecoperformance or the performance of eco-ports.

Environmental information systems (EIS) use a variety of tools and technologies to facilitate the interpretation of environment-related information towards improved decision making. Integrated technologies of the information systems include:

- Computer simulation models;

- Relational databases;

- Expert systems;

- GIS; and

- Decision support systems.

In the strategy of European transport, maritime traffic has an important role in the national economy, thanks its low cost and relatively low impact on the environment. 
Today's intensification of maritime traffic associated with large pollution of marine water, soil and air which common policies dictate protection and monitoring.

"Environmental pollution is the introduction of direct or indirect materials, vibrations, energy, heat, radiation, noise and biological factors in the air, water and earth, which can alter the qualities of the environment and harm the quality of life".[1]

These global developments are motivated to carry out a study in this field by considering the case of Albania, the first gate of Corridor 8 of transport network in European Union.

Analysis of current situation highlights many problems and we study patterns and offer recommendations regarding the application of environmental information systems inside of the Integrated System of Information and Statistics of Albanian sea ports.

Globally, it is aimed to create a European network of eco-ports based on information systems that monitor environmental data port and provide quality information on sustainable management of the environment.

\section{Methodology}

The study will focus on:

- A sustainable eco-management of European ports

- The improvement of ports eco-performance

- The monitoring systems of environmental parameters in ports

- $\quad$ EIS in support of eco-ports network

- The information exchanging platforms in favor of solving environmental challenges

- Applications of included EIS in Integrated Systems of Information and Statistics.

We are going to study Environment and Information Systems in the case of Albania, focused on the port of Durres region as the largest Albanian port situated very close to the urban area.

Studying of eco-performance of Albanian sea port in this point of view, will give us the level of benefits regarding the application of environmental information systems in the role of information exchanging platforms in favor of solving environmental challenges.

A sustainable eco-management of European ports meansfirstly the principle of sustainable development.[2]

Environmental protection based on "Environmental management system" encompasses the institutional framework, policies, action plans and administrative and technical measures for environmental protection, certified by international organizations ISO and EMAS.

In the light of the results of the review, establish an effective environmental management system aimed at achieving the port organization environmental policy defined by the top management. The management system needs to set responsibilities, objectives, means, operational procedures, training needs, monitoring and communication systems.[3]

The improvement of ports ecoperformance requires preventative action of water pollution, air, land and natural resource conservation in port areas and urban areas near the port, in cooperation with research centers and local authorities.

The monitoring systems of environmental parameters in ports include monitoring of quality, pollution and the damage to biodiversity, natural phenomena and emissions, and is mandatory.

Environmental monitoring carried out in accordance with the national monitoring program, which provides indicators of environmental quality, emissions, pollution and damage, natural phenomena, biological diversity, the sampling methodologies, measurement, data processing and reporting of their publication.

\section{EIS in support of eco-ports network}

In attempting to guarantee a sustainable sea traffic development, eco-ports network aims to set up a permanent PAN-EU network to develop, strengthen and transfer coordinated initiatives of cooperation for ecomanagement of PAN-EU corridor ports. 
Thus, only the application of common European standards and regulations, of a common policy for the protection of marine environment, and an updated and integrated monitoring network will enable the prevention of environmental impacts inalienable.

\section{The information exchanging platforms in favor of solving environmental challenges}

Understanding environmental condition is an important element of coastal resource management. This usually requires a great deal of data, and an information system can provide tremendous assistance in organizing, managing, understanding, and reporting this information.

Strategy for information exchange will be based on international information exchange and sharing of national information.

Applications of EIS included in Integrated Systems of Information and Statistics.

EnvironmentalInformation Systems are an integral part of Integrated Systems of Information and Statistics that will manage the harbor.

During the study will be raised three hypotheses:

$\mathrm{H} 1$-The Albanian port area can't be part of the European network of eco-ports based on environmental Information systems.

H2- Can Albanian port area be part of the European network of eco-ports?

H3- The Albanian port area can be part of the European network of eco-ports based on environmental Information systems.

The results of the study will be based on the observation of Albanian portseco-performance supporting by EIS.

This paper will conclude with recommendations regarding the application of environmental information systems in improving the quality of the monitoring of Albanian sea ports eco-performance.

\section{Research literature}

Maritime transport is the prominent mode for trade between EU and third-countries carrying approximately $40 \%$ of internal market freight flows and $90 \%$ of EU external trade. As a consequence reducing the environmental footprint of waterborne operations within acceptable limits is a key challenge for sustainable transport.

Environmental pollution caused by shipping operations includes:

- Air pollution and Greenhouse gases GHG[z1] (Carbon Dioxide, Sulphur Dioxide, Nitrogen Dioxide, particulates etc)

- Noise

- Waste (marine debris, etc)

- Solid Waste, Sewage

- Ballast Water/Waste Water

- Oil/Sludge

The EU's Integrated Maritime Transport Policy is committed to a reduction of pollution by shipping, particularly in coastal waters and around/in port areas (Ref: An Integrated Maritime Policy for the European Union Commission Staff Working Document, 10.10 2997, SEC (2007) 1278) and it is likely that legal/regulatory requirements covering this area will become more and more stringent in the future.

\subsection{The role of Information and Communication Technologies in developing a sustainable eco-management of European ports}

According to Europian Environment Agency - 2010 "As an interface between land and sea, European coastlines provide vital resources for wildlife, but also for the economy and human health and well-being.

- Multiple pressures, including habitat loss and degradation, pollution, climate change and overexploitation of fish stocks, affect coastal ecosystems. 
- Coastal habitat types and species of Community interest are at risk in Europe; two thirds of coastal habitat types and more than half of coastal species have an unfavourable conservation status.

- Integrated and ecosystem-based approaches provide the foundation for sustainable coastal management and development, supporting socio-economic development, biodiversity and ecosystem services. Coordinated action at the global, regional and local levels will be key to sustainable management of coastal ecosystems".

Understanding environmental condition is an important element of coastal resource management. This usually requires a great deal of data, and an information system can provide tremendous assistance in organizing, managing, understanding, and reporting this information.

Together, relational databases and GIS provide powerful tools for organising and analysing environmental data.

There are a lot of Information Systems about environment management that are EMIS, GAIA, EARSS, NOE; for Marine Water Resources: CYPRUS, NILE-DraSS, OPTIMA, SMART, KELANTAN, YANGTZE; for Air Quality: WEBAIR, NOe, CYPRUS, MALTA, TEHRAN, GULF, BRAZIL, KOREA, SUTRA; for Risk:A-TEAM and for Marine Systems:ICZM.

\subsection{Implementation of ICZM tools in eco-ports pro}

The European Commission defines the Integrated Coastal Zone Management of coastal areas (ICZM) to achieve the objectives of eco-ports, general principles and tools that are used in integrated management of coastal zones are provided.[4]

Implementation of ICZM tools in eco-ports project means:

a) The integration principle

b) Integrated network

ECOPORT8 set up a permanent PAN-EU network to develop, strengthen and transfer coordinated initiatives of cooperation for eco-management of PAN-EU corridor ports. Through PAN-EU networks (of scientific organizations and authorities) in eco PAN-EU corridor ports, the basis for eco certification of ports is to be created, in line with EU best practice, disseminating good practice among authorities, port workers and end users.

Focusing on different aims and interests, an articulated dissemination plan is planned, including meetings, a Website, leaflets, a documentary, etc. In terms of durability, the constitution of a network board should be noted which will encourage a continuous process of horizontal issues-solving. Moreover, the pilot installations will be operative after the conclusion of the project, as will various dissemination tools. The project will ultimately allow the port Authorities involved to move towards self-certification. Furthermore, the WEBGIS will make data sets available, useful in research applications and the implementation of new monitoring systems.

The implementation of an integrated system (WEBGIS, WP5) able to collect and redistribute all the environmental information necessary to acknowledge the environmental impact both of a single port and of the whole network is considered as one of the project's main activities. Thus, Port Authorities will be in the condition of self-certificate their activities according to UNI EN ISO 14000 standards. The challenge could be to certificate not only the ports, but the network, too.

\section{c) EU marine observation and data network}

The outputs as a monitoring network plan of the eco-ports will permit a shared vision on environmental policy, design of a monitoring system and define better procedures and implementation of pilot monitoring. This will allow the collection of the first environmental data to be published on a WEBGIS. Results are then integrated into the Web-GIS/SDSS platform to be developed in WP5.

An embryonic fixed monitoring system within the 2 pilot sites developing a shared tool of the eco network, guaranteeing trans-national cooperation is a part of work program, WP5. 
The monitoring network will allow the definition of the current situation of the principal sensitive parameters, and the setting up of an effective risk management system to prevent irreversible environmental damage.

\section{d) European network for maritime surveillance}

Maritime surveillance is critical for the safe and secure use of marine space. The monitoring network of ecoports will be considered as a contribution in this part of integrated coastal zone management.

\section{e) Coastal GIS}

GIS technology became widely used essential tool for activities such as monitoring of environmental processes and resource uses, and designing optimum decision-making apparatuses. Today Coastal GIS is important tool in integrated coastal zone management.

Elaboration and input of acquired data into a WEBGIS, made public through the eco-ports website. Such a system allows for comprehensive data management (interrogation, extraction, comparison, overlapping, graphic output and tabulation). The on-line GIS System will be regularly up-dated and integrated with specific information services already in use.

\section{e) Maritime spatial planning}

Land use planning in ports has a largely terrestrial focus and often do not address how port development may affect the sea and vice-versa. The challenges that emerge from the growing competing uses of the sea are from maritime transport, fishing, aquaculture, leisure activities, off-shore energy production and other forms of sea bed exploitation. Maritime spatial planning is therefore a fundamental tool for the sustainable development of marine areas and coastal regions, and for the restoration of Europe's seas to environmental health.

\section{WebGIS challenges}

The update of WebGIS about environmental data by ITC is emergency for harbour districts. This database will create to represent the port data and logistic intermodal infrastructure. It's neccessary an professional software to manage the database.

Since 1994, the vision of EcoPorts has been to create a level playing field on port environmental management in Europe through the sharing of knowledge and experience between port professionals. Serving the principle of "ports-helping-ports" EcoPorts brought together a network of port professionals from several European ports committed to exchange views and practices and to commonly work towards the improvement of the sector's environmental performance in line with the principles of voluntary self regulation.

Applied systems analysis, artificial intelligence and ICT provide the methodological basis for the environmental applications, information and multi-criteria decision support systems. Resource efficiency and sustainable development are the overriding themes.

Our dedicated high-performance environmental management information and decision support systems combine advanced (dynamic, distributed, high-resolution, non-linear, stochastic) simulation and optimization models, data analysis.

\section{GIS and expert systems}

Integrated solutions use a modular, distributed and web based client-server architecture for cost-efficient use of state-of-the-art information resources, easy access and use. Multi-media user interfaces, Internet/Intranet access, and a broad range of supporting services from dedicated research and development to complete ASP outsourcing solutions with Internet access for distributed and mobile clients are available.

We support user groups ranging from technical specialists and decision makers to the general public with active stakeholder involvement and participatory decision support tools. 
Our strength is the smooth integration of environmental sciences, applied systems analysis and operations research, engineering and socio-economic analysis, with state-of-the-art information technology: simple webbrowser based access, embedded training components and AI, high-performance cluster computing.

\section{Environmental Software offers:}

Integrated software solutions for complex and distributed (Internet/Intranet) environmental information and decision support systems. These systems are available as fully web based solutions including remote maintenance and support, and alternatively are available as turn-key systems installed on powerful, reliable, and secure Linux/UNIX servers supporting PC based web clients on Intranet and Internet TCP/IP connections.

An embedded GIS provide tools for the composition, selection, and display of background maps and spatially distributed data.

They include any user defined combination of individual overlays of line features, polygons and raster background images such as satellite imagery and high-resolution aerial photography.

The embedded GIS tools include interactive map import and export (ArcView/Info compatible shapefiles of *.e00 export files) map composition, but also the management of spatially distributed model results (rasters and matrices) and their numerical export, as well as the animation of dynamic model results.

GIS data are used as background and spatial reference for all georeferenced data and as model inputs (e.g., digital terrain model, land use, bathymetry, surface characteristics, location of emission sources), but also to support post-processing of model results such as environmental impacts and population exposure.

WEBGIS is implemented in an open, object-oriented client-server architecture, fully web-enabled and Internet based, supporting the seamless integration of databases, GIS, simulation and optimization models, and analytical tools into a common, easy-to-use framework. This includes a multimedia user interface with Internet access (using a standard web browser as the only client software required), a hybrid GIS with hierarchical map layers, object data bases, time series analysis, reporting functions, an embedded expert system for estimation, classification and impact assessment tasks, and a hypermedia help- and explain system.

Real-time data management, simulation and non-linear multi-objective, multi-criteria optimization modeling, with data assimilation, forecasting, and reporting, and support for operational management can be provided with a real-time rule-based expert system. Auxiliary tools manage user requirements and stakeholder preference structures for the participatory optimization.

\section{Monitoring of air quality}

WEBGIS maintains a range of dynamic simulation models for atmospheric dispersion and photochemical reactions, and dust entrainment, transport and deposition, that can be used both for automatic, scheduled forecasting and now-casting runs (modeling cum monitoring, data assimilation) but also interactively for scenario analysis, planning, and environmental impact assessment.

The regional air quality modeling is driven by 3D prognostic meteorological models (MM5 or WRF) and the nested grid photochemical model CAMx producing regular 5 day (120 hours) forecasts that can be updated every six hours, and use local monitoring data of ambient air quality for real-time data assimilation.

Within this framework local models for the individual sources and source groups of the industrial estate are operated automatically, on an hourly now-casting basis and againwith the option of real-time data assimilation.

Another important application is emergency management: in the case of an accidental release of a hazardous substance that evaporates at least in part to the atmosphere, the release of a toxic, flammable or explosive gas, or a chemical fire and potentially toxic smoke, the readily available detailed meteorological forecasts and the atmospheric dispersion models can immediately be used to forecast the evolution of an emergency over time and its spatial extent, providing valuable information for first responders, fire fighters, and the emergency response teams in general.

EIS maintains a range of dynamic simulation models that can be used both for automatic, scheduled forecasting and now-casting runs modeling cum monitoring, but also interactively for scenario analysis, planning and environmental impact assessment. 


\section{Coastal water quality}

For industrial parks in coastal locations major harbors and related activities, coastal water quality for harbor basins is available, based on the ROMS/TOMS 3D dynamic flow and transport model system. Combined with the meteorological forecasting of up to a 10 days, thisprovides a powerful tool to marine support spill management and coastal protection.

By E. van Hooydonk 2006 "EMIS tools include the online environmental self-audit for ports Self-Diagnostic Methodology, an online database and a standard environmental management scheme which can be applied in port communities all around Europe." [5]

WEBGISis designed as a modular system; it can integrate a range of information resources: Considering the Platform support, WEBGIS is currently supported for Linux systems, and UNIX servers (e.g., SUN Sparc/Solaris). The system is designed for distributed, web-based access, supporting multiple clients through the Internet.

The main logical server (from a single machine to a HPC cluster) maintains the data bases, models, and dynamic page generation for the interactive tools using server-side technologies, mainly CGI and PHP, and an Apache web server. As an alternative, an X11 based version, sharing the same data bases, is also available.

Clients can be PC based, and need a standard web browser (PC based, distributed WAN clients) or an X11 server/emulator (LAN clients).

For a WEBGIS server, a high-end multi-processor PC/workstation or server is recommended; this may be augmented by a cluster of dedicated servers for specific tasks such as the RDBMS, web server, compute servers, etc. Configuration depends on the number of simultaneous users and the models installed; computing power on-demand for demanding models such as the optimization tools can be supplied through a distributed ASP model, together with complete mirror installations including on-line technical and application support, real-time CRM, distance learning components, and backup and disaster recovery options.

A graphics resolution of $1280^{*} 1024$ (true color) is required for the X11 platforms; PC based clients (web browser) require at least $1024 * 768$ pixels screen resolution.

From 1 January 2011, during the Greenport Conference (Venice, 23 - 24 February 2011) European Sea Ports Organization (ESPO) has presented the "New EcoPorts" as A New Era for Ecoports in Europe, using on-line systems for evaluating environmental performance of ports.[10]

The new updated versions of SDM and PERS has been officially launched as part of the services that ESPO provides. The management of the EcoPorts network of ports within ESPO will be facilitated by a new online system that will be replacing the current EcoPorts website. The new system incorporates the new SDM as an online-based tool and provides visibility and credit to ports that achieve and maintain an "EcoPorts port" status.

It will also manage and disseminate the well established EcoPorts tools Self Diagnosis Methodology (SDM) and Port Environmental Review System (PERS) within Europe and in neighbouring countries. The EcoPorts tools are now available to the whole ESPO membership and this is expected to expand their use by European ports and to broaden the EcoPorts network.

It will be incorporating the new SDM as an online-based tool and will be providing visibility and credit to ports that achieve and maintain an "Ecoports port" status.

The latter is achieved by any European port registering within the new system and completing the online SDM questionnaire, thus contributing to the up-to-date maintenance of the European benchmark of performance in port environmental management. The "EcoPorts port" status will be then allowing ports to access, implement and get certified by PERS, which is the only environmental management standard that is specific to the port sector.

During the last 15 years, the European port sector has achieved significant progress in the field of environmental management and this has been largely driven through the long standing close cooperation between ESPO and Ecoports. The new way forward is warmly welcomed by all parties involved as it is expected to extend the achieved progress and the sector's efforts through the principle of voluntary self regulation.

The tools of EIS for Ecoport are Self Diagnosis Method (SDM), Port Environmental Review System (PERS) and EcoPorts Network Platform.

Self Diagnosis Method (SDM) is a well-established and widely adopted, time and cost-efficient methodology for identifying environmental risk and establishing priorities for action and compliance. SDM is a 
concise checklist against which port managers can self-assess the environmental management programme of the port in relation to the performance of both the European port sector and international standards. Individual port responses are treated confidentially and SDM is by no means a "pass" or "fail" exercise.

The Port Environmental Review System (PERS) has firmly established its reputation as the only port-sector specific environmental management standard. PERS stems from work carried out by the ports themselves and it is specifically designed to assist port authorities with the functional organisation necessary to deliver the goals of sustainable development. While incorporating the main generic requirements of recognised environmental management standards (e.g. ISO 14001), PERS is adapted to deliver effective port environmental management and its implementation can be independently certified.

EcoPorts Network Platform enables European port communities to exchange environmentally effective solutions, and work together in collaborative projects addressing sustainability issues in ports and the logistic chain.

The EcoPorts know-how, network, products and services are available for all our Network Partners. The ultimate goal of EcoPorts Foundation (EPF) is to create a level playing field in Europe in port-related sustainable management issues.

To achieve this goal EPF initiates the following activities:

- Network activities to exchange good practices and experience

- Development and implementation of tools to collect and transfer practical know-how between port communities in Europe

- Development and implementation of new initiatives to implement best practices or to develop new technologies, procedures etc.

Internet, a client/server system, is a perfect means of GIS data accessing, analyzing and transmission. The World Wide Web, FTP (file transfer protocol) and HTTP programs make it convenient to access and transfer data files across the Internet.

Using Internet for GIS makes it easy access to acquire GIS data from diverse data sources in the distributed environment. The geospatial multicriteria decision analysis in a client/server environment is an important and challenging task for the GIS community because of narrow Internet bandwidth for large geospatial data sets.

"The multicriteria technique of Analytic Hierarchy Process (AHP) is used to derive the eigen vectors with the given multiple constraints of conflicting criteria and aims at selecting optimal alternative from the available sets. However, the evaluation recognizes the importance of expert knowledge when assigning the weights for the best spatial priorities. The Multicriteria Spatial Decision Support System (MC-SDSS) software development uses ASP, ArcIMS 9.0, ArCSDE9.0 and Oracle 9i data server in the web GIS environment. The database organization of spatial and non-spatial data is done in the RDBMS environment using ArcSDE and Oracle 9i data server".[8]

Expert System in Artificial Intelligence, that have enhanced productivity in business, science, engineering are a future solution and for the environment management.

\section{Subject (Albanian case)}

Port Authority, in accordance with national and European legislation, checks pollution in the port basin supporting the initiative for clean technologies at ports of Eighth Corridor partners of Bari-Durres-Varna.

GIS environmental updated data systems, based on ICT are an emergency. Such a database managed by professional software should be established to present data port terminals and logistics infrastructure.

The novelty of this article is confronting of the largest Albanian port with eco-European ports, in point of view to prevent the pollution ofwater, air and landbased in environment information systems EIS.

Durres Port Authority (DPA) operates in the following areas:

- Verifies polluting sources in the tank, which continuously measures to eliminate them, by involving boat operator to clean the basin and staff of APD's waste coming from the basin.

- Controls the execution of oilseed waste collection, sewage, waste and processing waste after cleaning by water companies.

- To fulfill all obligations required by Article 40 of Law nr.9130 dt.8.9.2003 "For Port Authority", the International Convention for the prevention of marine environment pollution (MARPOL 73/78), SA 
8000 Ethics Code, Law on civil Emergencies, organizes and plans the environmental performance of the Port for its certification standards required by the EU.

- It Cares to prevent pollution of the soil during activities related to operations and the movement or parking of vehicles. For this task, cooperate with the forwarding agency, responsible for processing of goods.

- Doing research on the amount of waste generating activities during the related development (projects) and operations.

\section{Environmental monitoring system}

Monitoring of Port Basin, anchorage area, land area etc. is covered by different operators of the port. In case of pollution in sight, a number of operators in port are obliged to inform.

These operators might be the ship's captain or crew, stevedores, pilots, mooring men, agents, crane operators, security, etc.

"Environmental indicator" [1] is a variable that gives a concise and simple information about an environmental phenomenon, making it perceptible by assigning a numerical value, measurement and communication. Environmental phenomena related to environmental qualities of its components, environmental emissions, environmental pollution and damage, and extent of damage to biodiversity or its conservation and measures taken to protect the environment.

In port areas usualy are measured environmental indicators of soil, water and air.

"Environmental monitoring"[1] is the collection, evaluation and generalization of environmental data through observation, continuing or recurring, of a group of environmental indicators, qualitative and quantitative components that characterize the environment and their changes from the impact of natural and human factors.

Environmental monitoring carried out in accordance with the national monitoring program, which provides indicators of environmental quality, emissions, pollution and damage, natural phenomena, biological diversity, the sampling methodologies, measurement, data processing And reporting of their publication.

Actually, there is no monitoring system relating to the Bathymetric surveys, Geomorphologic surveys. Water quality analyses are performed in a campaign way by the Public Health Institute contracted by DPA Environmental Directory for basin area: 1 time/year.

Air quality analyses are performed in a campaign way by the Public Health Institute contracted by DPA Environ-mental Directory 1 time/year for: LNP, PM10, NO2. SO2, CO, HC.

Noise impact analyses are performed in a campaign way by the Public Health Institute contracted by DPA Environ-mental Directory 1 time/year.

DPA is developing a project named "ECOPORT 8" [10] (Janar 2009- Dhjetor 2011)thatseeks to exceed the difficulties in the implementation of environmental policies, even benefiting from the economic and social advantages (the increase of maritime traffic) and healthy environmental conditions.

Expected outputs and results are:

- Sustainable SEE (South East Europe) network

- A initial environmental analyze of 6 ports and installation of three fixed pilot sites as an embryonic network for monitoring and developing.

- Update of WebGIS for environmental data, integrated information tools, to achieve better security, efficiency, ecological quality control.

WebGIS will offer a number of free, web-based services. These services are provided to the greater research community to assist in creating the fundamental basis for geospatial-related research, geospatial data. While many web-based and/or PC-based services/programs are available for creating and manipulating geospatial data, WebGIS offers direct access to the latest cutting edge research on geocoding, address parsing, normalization and standardization, and open source geospatial mapping and visualization.

The challenge of WebGIS lies in creating software systems that are platform independent and run on open TCP/IP-based networks, that is on any computer capable of connecting to the Internet (or any TCP/IP-based network) and running a Web browser.

Many strategies can be employed to add GIS functionality to the Web: 
- Server-side strategies allow users (clients) to submit requests for data and analysis to a Web server. The server processes the requests and returns data or a solution to the remote client.

- Client-side strategies allow the users to perform some data manipulation and analysis locally on their own machines.

- Server and client processes can be combined in hybrid strategies that optimize performance and meet special user needs.

- Real-time GIS involves feeding data directly into the system from sensors or real-world sources as the data is generated.

- The advantage of using Internet-based systems is that data from many sources can be delivered across the open network without the need for dedicated cable, telephone, or radio feeds.

\section{Conclusion}

After this detaileds tudya nd analysis is noted that standards of monitoring the eco-performance of Albanian ports are not in the right level.

"A major challenge in Europe and globally is to organize the vast array of already collected environmental data and information and to integrate these, where desirable, with existing social and economic data. This data should be made available together with tools that allow experts to do their own analyses and to communicate their results in ways which policy makers and the public can readily understand and use as a basis for their own actions. At the same time, Member States and EU institutions need an efficient and modern reporting system to fulfill their legal obligations under European Union and international environmental policies and legislation, thus avoiding double, overlapping, and redundant reporting efforts. The Shared Environmental Information System for European aims to address these challenges." [4]

This paper will conclude that application of environmental information systems as an integral part of the Integrated System of Information and Statistics of Albanian sea ports will be the final solution.

It is the time to integrate this EIS of Albanian ports with National and European Environmental Information Portal, to establish the operational Regional Database and Information Platform including expert system for pollution mitigation, to update of environmental sensitive indices for all region of Durres port district, to implement a satellite monitoring pilot study in detecting pollution (illegal or accidental) and visualization of all geo-spatial information through GIS mapping.

This will be the future challenge; tocreatea European network of eco-ports based on information systems especialy based in Expert System in Artificial Intelligence.

\section{References}

1. http://www.informare.it/news/gennews/2011/20110299-ESPO-presenta-portale-Ec

2. Law nr.8934, (2002) "For Environment Defense"

3. http://ec.europa.eu/environment/seis/what.htm

4. Stojanovic TA and Wooldridge, (2003) C.F. -"Specification and formulation of the tools and methodologies required for the development of an Environmental Management Information System (EMIS) for the European port sector". Report EPRCWTS010403WP1_1EMISconcept. A Report Submitted to the EU ECOPORTS Project, General Directorate of Transport and Energy of the European Commission,

5. 2010 "Albania Integrated Coastal Zone Management and Cleanup Project - Environment and Social Safeguards Framework"

6. E.vanHooydonk(2006) "The impact of EU environmental law on waterways and ports"

7. Dr.Kurt FEDRA (2007) "Water resources simulation and optimization: a web based approach"

8. http://ecologic.eu/791

9. Karnatak H. Saran S. Bhatia K. (2007) "Multicriteria Spatial Decision Analysis in Web GIS Environment"

10. http://www.apdurres.com.al/projektet.html 